\section{Transfer following two-choice differential reward learning in children*}

\author{
KATHERINE W. ESTES \\ The Rockefeller University, New York, N.Y. 10021
}

Following training to criterion simultaneously on two discriminations involving pairs of stimuli rewarded with 4 vs 2 or 1 vs 0 tokens, 93 children from prekindergarten to second-grade classes received transfer trials (members of one pair tested against stimuli from the other pair) and single-stimulus tests (Ss stating reward magnitude associated with each stimulus separately). Younger children appeared to transfer on the basis of approach-avoidance tendencies developed during training, whereas older Ss used information about absolute rewara magnitudes. Verbalization of reward magnitudes increased in accuracy with age, but was only imperfectly related to transfer.

How do processes involved in effective transfer of choice behavior following differential reward learning develop with age and experience? Both animals and human adults readily learn to choose the stimulus with the higher assigned reward in a two-choice situation. Further, adult human Ss (Estes, 1966) and sophisticated monkeys (Meyer, LoPopolo, \& Singh, 1966), once having learned several two-choice problems, show considerable skill in responding appropriately to new pairings of the stimuli.

This transfer behavior can readily be interpreted in terms of a cognitive or informational theory of reward (Atkinson \& Wickens, 1971; Estes, 1969; Nuttin \& Greenwald, 1968). It is assumed that $S$ acquires information regarding the relations between each of the stimuli and its assigned reward and then adjusts his choices to conform to his state of information in both training and transfer situations. However, transfer can often be accounted for on the perhaps more parsimonious assumption (Thorndike, 1931 ) that during training $S$ associates approach and avoidance responses with the members of stimulus pairs which yield higher and lower reward, respectively, then on transfer tests simply continues to approach the previous "winners."

Information relevant to deciding between these views may be obtained

*This investigation was supported by Grant GM 16735 from the National Institute of General Medical Sciences. The author would like to express her appreciation to Mr. Ernest Seegers, Mrs. Alexandria Church, and Mrs. Anne Harrison for making available facilities of the Friends Seminary School and to the teachers-Mrs. Helen Baxter, Mrs. Linda Chu, Mrs. Jane deSeife, Miss Mary Gross, Mrs. Madeleine Jeffrey, Miss Nancy Liddell, and Miss Judith Young-who suffered our interruptions so cheerfully. The author is grateful to George Estes for constructing the apparatus and the stimulus blocks. from suitably designed transfer studies. Suppose a stimulus pair, A,B, with reward values 8 and 4 , respectively, and a pair, C,D, with reward values 2 and 1, respectively, are presented in a random sequence until $S$ learns always to choose A over B and $C$ over $D$. What should one expect if $S$ is now offered a choice between $B$ and $C$ ? Will he choose the stimulus he has previously learned to approach (C) or the one with the higher reward value (B)? Meyer, LoPopolo, \& Singh (1966) found that monkeys strongly prefer the stimulus of higher absolute value under these conditions, a result that is hard to account for on the basis of differential approach and avoidance tendencies. It would seem that the animals must have built up in memory some representation of the reward value of each stimulus. However, it should be noted that the monkeys in the study of Meyer et al were highly sophisticated in discrimination learning situations. Thus the question arises as to whether the ability to transfer on the basis of absolute reward values might have been the result of a lengthy learning process prior to the experiment.

Further, it should be noted that the approach-avoidance and the informational conceptions need not be regarded as mutually exclusive alternative interpretations of transfer behavior. Rather, we might regard them as referring to processes which can coexist in the same organism, with the former being perhaps the more primitive and the latter becoming dominant with increasing age and experience. To explore this possibility, the paradigm of the Meyer et al (1966) study is applied to children, using a range of ages which may yield information as to developmental changes in the control of choices by rewards.

We are interested particularly in the possibility that the youngest children might transfer on the basis of approach and avoidance tendencies, but older ones on the basis of information concerning absolute reward values. Such a result would fit in with other findings on the progressive increase with age in the use of mediators in discrimination learning (Kendler \& Kendler, 1968). In particular, we shall attempt to determine whether a developmental trend can be observed among young children (1) in the tendency to make appropriate choices on test trials on the basis of magnitude of reward, and (2) in the ability to state correctly the values associated with specific stimuli. The relationship existing between these two variables will be of particular interest.

Each $S$ was tested on three problems: (1) A junk object discrimination problem with 1 - or 0 -token rewards was used for familiarization. (2) Problem I involved two pairs of stimuli with reward values of 4 and 2 assigned to one pair and values of 1 and 0 to the other; after each $\mathbf{S}$ was run to criterion or for a maximum of 60 trials, he was given transfer tests followed by single-stimulus tests. (3) Problem II was identical to Problem I, except that it involved different stimulus blocks. SUBJECTS

The Ss were all ${ }^{1}$ of the children enrolled in four classes at The Friends Seminary School (Table 1). The classes used were prekindergarten (K-4), kindergarten $(\mathrm{K}-5)$, and the first and second grades.

$$
\text { APPARATUS }
$$

A portable WGTA, a modification of that described by Zeaman \& House (1963), was constructed of plywood and painted gray. The overall dimensions were 24 in. wide $x 19$ in. deep $\times 8$ in. high. A $19 \times 16$ in. drawer was mounted on a KV drawer slide in the box. The back portion of the top of the box $(15 \times 24$ in.) was hinged and rested on hinged sidepieces so as to make a 39-deg angle with the stationary front segment, $2^{3 / 4}$ in. wide. This arrangement permitted $\mathrm{E}$ to manipulate coins and stimulus blocks without $S$ being able to see her hands. In the front portion of the drawer were three aluminum wells, 2-5/8 in. across, lined with masking tape to muffle the sound of coins being placed in the cups. The cups could be covered by $3 \times 3$ in. stimulus blocks. Only the outside two cups were used in this experiment, the center cup being covered with a flat gray block.

\section{PROCEDURE}

The instructions to $\mathrm{Ss}$ were a paraphrase of those used by Kendler, Kendler, \& Wells (1960). The Ss were instructed to try to obtain as many 
Table 1

Characteristics of $\mathrm{Ss}$ in Each Grade Level

\begin{tabular}{llllll} 
& N & $\overline{\mathrm{CA}}$ & $\overline{\mathrm{MA}}$ & $\overline{\mathrm{IQ}}$ & N Boys \\
\hline K-4 & 25 & $5-2$ & $6-8$ & 127.52 & 13 \\
K-5 & 22 & $5-9$ & $7-5$ & 128.68 & 10 \\
First Grade & 22 & $7-3$ & $9-6$ & 127.50 & 10 \\
Second Grade & 24 & $7-10$ & $11-2^{*}$ & $140.83^{*}$ & 12 \\
\hline
\end{tabular}

*Second graders' MAs and IQs are based on group tests whereas data for other grades are based on the Stanford-Binet or WISC.

coins as possible so as to have them to trade for a prize at the end of the session. In the junk object discrimination, a coin would be found in the cup in the apparatus if $S$ selected the "winner," but only one block could be lifted on each trial. It was emphasized that if $S$ attended to the blocks, he should soon be able to find a coin on every trial. Each time $S$ found a coin, E said, "Good." The positions of the stimuli were randomized within blocks of four trials. Trials continued until $S$ had given correct responses on seven of the eight trials in two consecutive four-trial blocks. Then $E$ held up the stimuli and asked S, "Which was the winning block?' All Ss were able to identify it, some verbally and some by pointing.

Since the purpose of the junk object problem was to equalize Ss with regard to familiarity with the procedure, it is of interest to observe that there were no systematic age differences in the number of four-trial blocks required to reach criterion (see Table 2).

Following the junk object problem, $E$ explained that in the next problem there would be more blocks, that different blocks would have different numbers of coins under them, and that $S$ would have to count the tokens found on each trial and tell $E$ how many there were.

Each block of four trials included two presentations of each pair of stimuli, once with each of its members in the right and then in the left position. The order of stimulus presentation was random within blocks, except for the first four-trial block, during which the members of one pair (say, 4 vs 2 ) were presented with each stimulus in the right and the left position before the second pair (1 vs 0 ) was introduced and similarly presented. To assure exposure to the reward magnitude for each stimulus, if $S$ did not look under both of the blocks exposed during the first two trials and during the third and fourth trials, E said: "Would you like to look under the other block to see if you chose the one with more coins under it?" At the end of each trial, S counted the tokens and $E$ repeated the number in a pleasant voice. No other social reinforcement was given. Occasionally a child would spontaneously look under the second block. On such trials, E repeated the stipulation about not looking under more than one block on any given trial.

The $S$ continued to a criterion of seven correct responses in two successive four-trial blocks (i.e., at least $100 \%$ correct on one pair and $75 \%$ on the other) or to a maximum of 60 trials. Regardless of level of performance reached, a block of eight transfer trials was administered with each stimulus from the 4-2 pair presented with each of the stimuli from the 1-0 pair. These new pairs were presented in a random order once, and then the pairs were presented with the left-right position of the stimuli reversed.

After the eighth transfer trial, E held up the individual blocks in succession and asked, "Each time you chose this block how many coins did you find?" The S's replies were recorded. The E merely repeated S's reply, giving $S$ no information concerning errors. At this point, S's cup of tokens was likely to be full, so $S$ chose a prize from those available (raisins or candy).

Problem II was presented in the same manner as Problem $\mathrm{I}$. The $\mathrm{S}$ was allowed to choose two prizes at the end of Problem II, so that each child received a total of three items.

$$
\text { STIMULI }
$$

Junk objects included a toy automobile, a small padlock, a toy wristwatch, a cookie cutter, a whistle, and a measuring spoon. The wooden blocks on which these items were mounted were painted gray.

The experimental problems involved two pairs of wooden blocks painted white. On each was mounted one of eight forms $(\square,-, \sigma, \square, \because, \mathrm{T}, \mathrm{X}$, or $*)$ in one of five colors (red, green, blue, yellow, or orange). The blocks were paired randomly. Pairs were presented in random sequences within blocks of four trials with the exception of the first block of four trials in Problems I and II.

\section{RESULTS}

Acquisition Choice Data

There was a clear tendency for speed of learning to increase with CA. The percentages of $S s$ responding correctly to seven of the eight pairs in two successive blocks of four trials on Problem I were 68, 73, 82, and 92 for the four groups, in order of ascending grade level; corresponding percentages on Problem II were $80,8 \varepsilon, 95$, and 100. The number of four-trial blocks required to reach criterion tended to decrease with grade level. In the case of Problem II, the trend showed no reversals; however, on Problem I, K-5 Ss learned in fewer trials than did first graders (see Table 2).

Transfer Choice Data

On the eight transfer trials following acquisition, the frequency of choices of the more highly rewarded block (henceforth termed "correct" choices) increased with CA, slightly for the first problem and substantially for the second. In the ascending order with grade level, overall mean proportions of correct choices were $.62, .63, .68$, and .66 on Problem I and .63, .73, .74, and .86 on Problem II. Critical ratios for deviations of these means from a chance value of .50 were significant at the .01 level for all groups on both problems.

Although analyses of variance of total transfer scores (total number of correct choices on eight trials) revealed no significant effect of age on Problem I $(F=.34, \quad \mathrm{df}=3 / 89), \quad$ a significant effect of age was found on Problem II ( $\mathrm{F}=6.08, \mathrm{df}=3 / 89$, $\mathrm{p}<.001)$. Mean total number of correct responses on transfer trials increased with $\mathrm{CA}$ for the problems combined; mean transfer scores for groups in order of ascending grade level were $9.9 \quad(S D=3.0), \quad 10.9$ $(\mathrm{SD}=2.3), 11.4(\mathrm{SD}=2.8)$, and 12.1 $(S D=2.2)$. Although both age

Table 2

Medians and Semi-Interquartile Ranges for Number of Blocks of Four Trials Required to Reach Criterion for Each Grade Group

\begin{tabular}{|c|c|c|c|c|c|c|c|}
\hline \multirow[b]{2}{*}{ Grade Level } & \multirow[b]{2}{*}{$\mathbf{N}$} & \multicolumn{2}{|c|}{ Junk Objects } & \multicolumn{2}{|c|}{ Problem 1} & \multicolumn{2}{|c|}{ Problem 2} \\
\hline & & Median & $\mathbf{Q}$ & Median & $\mathbf{Q}$ & Median & $\mathbf{Q}$ \\
\hline$K=4$ & 25 & 2.9 & 3.0 & 6.8 & $8.5 *$ & 3.5 & 7.3 \\
\hline $\mathbf{K}-5$ & 22 & 2.4 & 2.5 & 4.0 & $8.6^{*}$ & 3.3 & 4.4 \\
\hline First Grade & 22 & 3.6 & 3.5 & 4.5 & 7.8 & 3.3 & 3.8 \\
\hline Second Grade & 24 & 1.9 & 1.9 & 3.0 & 3.4 & 2.7 & 2.8 \\
\hline
\end{tabular}

$* Q_{3}$ fell in the indeterminate (above 15 ) block range, since more than $25 \%$ of the $S s$ failed to reach criterion; evaluation of $Q_{3}$ was made on the assumption that all $S s$ would have reached criterion in the 16 th block of trials. 
$(F=2.96, \quad \mathrm{df}=3 / 89, \quad \mathrm{p}<.05)$ and problems $\quad(F=12.72, \quad d f=1 / 89$, $\mathrm{p}<.001)$ produced significant primary effects, an overall analysis of variance failed to reveal a significant Age by Problems interaction $(F=2.46, \mathrm{df}=3 / 89)$.

In view of the apparent absence of an age trend in transfer on Problem I, it is instructive to examine separately the Ss' responses on the two test trials involving any given stimulus pair. In Table 3 are presented, for each grade level, the percentage of Ss making correct choices on the first ard second test trial for each pair of stimuli. Comparison of first and second test trials for any given pair fails to yield a significant $\mathrm{CR}$ in any case; the fact that 21 of the 32 comparisons are in the direction of improved performance suggests that the outcome of the first trial is not without some influence, although only the values for the second-graders on Problem I are large enough to approach significance.

Moreover, an age trend is suggested in the degree to which Ss modify their responses on the basis of the first of the two transfer trials involving any given pair of stimuli. Of the $62 \%$ of the K-4 Ss who chose correctly on the first transfer trial for any stimulus pair of Problem I, 71\% continued to do so on the second trials for that pair, whereas, of $52 \%$ of the second-graders who made a correct first choice, $84 \%$ gave a correct response on the second presentation of the pair. Similar figures for Problem II show that of $57 \%$ of the K-4 Ss who made a correct first choice on a given pair, $77 \%$ made a correct choice on the second presentation of the pair; of $84 \%$ of the second-graders making a correct choice on the first presentation, $94 \%$ did so on the second presentation of the pair.

Analysis of the data in terms of the frequency with which Ss changed their responses between the first and the second transfer test trial showed clearly that more Ss who made

Table 4

Proportion of Expectations by Grade and True Values

\begin{tabular}{|c|c|c|c|c|c|c|c|c|}
\hline Group & $\begin{array}{l}\text { True } \\
\text { Value }\end{array}$ & $\mathrm{N}^{*}$ & $>4$ & 4 & 3 & 2 & 1 & 0 \\
\hline$K-4$ & $\begin{array}{l}4 \\
2 \\
1 \\
0\end{array}$ & $\begin{array}{l}47 \\
47 \\
46 \\
47\end{array}$ & $\begin{array}{c}.02 \\
.04 \\
- \\
-\end{array}$ & $\begin{array}{l}.58 \\
.30 \\
.35 \\
.17\end{array}$ & $\begin{array}{l}.02 \\
.09 \\
.09 \\
.06\end{array}$ & $\begin{array}{l}.15 \\
.23 \\
.13 \\
.09\end{array}$ & $\begin{array}{l}.11 \\
.13 \\
.24 \\
.09\end{array}$ & $\begin{array}{l}.13 \\
.21 \\
.20 \\
.60\end{array}$ \\
\hline $\mathrm{K}-5^{-}$ & $\begin{array}{l}4 \\
2 \\
1 \\
0\end{array}$ & $\begin{array}{l}36 \\
34 \\
36 \\
35\end{array}$ & $\begin{array}{l}.03 \\
.06 \\
.03 \\
-\end{array}$ & $\begin{array}{l}.81 \\
.24 \\
.22 \\
.08\end{array}$ & $\begin{array}{c}.06 \\
- \\
.06 \\
.03\end{array}$ & $\begin{array}{l}.03 \\
.38 \\
.11 \\
.10\end{array}$ & $\begin{array}{l}.06 \\
.12 \\
.53 \\
.08\end{array}$ & $\begin{array}{l}.03 \\
.21 \\
.06 \\
.69\end{array}$ \\
\hline $\begin{array}{l}\text { First } \\
\text { Grade }\end{array}$ & $\begin{array}{l}4 \\
2 \\
1 \\
0\end{array}$ & $\begin{array}{l}43 \\
43 \\
43 \\
43\end{array}$ & $\begin{array}{l}- \\
- \\
-\end{array}$ & $\begin{array}{l}.84 \\
.19 \\
.33 \\
.12\end{array}$ & $\begin{array}{l}- \\
.02 \\
-\end{array}$ & $\begin{array}{l}.09 \\
.47 \\
.23 \\
.14\end{array}$ & $\begin{array}{l}.07 \\
.19 \\
.30 \\
.09\end{array}$ & $\begin{array}{l}- \\
.16 \\
.12 \\
.65\end{array}$ \\
\hline $\begin{array}{l}\text { Second } \\
\text { Grade }\end{array}$ & $\begin{array}{l}4 \\
2 \\
1 \\
0\end{array}$ & $\begin{array}{l}48 \\
48 \\
48 \\
48\end{array}$ & $\begin{array}{c}.02 \\
.02 \\
- \\
-\end{array}$ & $\begin{array}{l}.92 \\
.21 \\
.37 \\
.04\end{array}$ & $\begin{array}{l}- \\
.02 \\
-\end{array}$ & $\begin{array}{l}.02 \\
.50 \\
.15 \\
.19\end{array}$ & $\begin{array}{l}.02 \\
.12 \\
.37 \\
.08\end{array}$ & $\begin{array}{l}.02 \\
.15 \\
.08 \\
.69\end{array}$ \\
\hline Total & $\begin{array}{l}4 \\
2 \\
1 \\
0\end{array}$ & $\begin{array}{l}174 \\
172 \\
173 \\
173\end{array}$ & $\begin{array}{l}.02 \\
.03 \\
.01 \\
-\end{array}$ & $\begin{array}{l}.78 \\
.23 \\
.32 \\
.10\end{array}$ & $\begin{array}{l}.02 \\
.02 \\
.05 \\
.02\end{array}$ & $\begin{array}{l}.07 \\
.40 \\
.15 \\
.13\end{array}$ & $\begin{array}{l}.06 \\
.14 \\
.35 \\
.09\end{array}$ & $\begin{array}{l}.05 \\
.18 \\
.11 \\
.65\end{array}$ \\
\hline
\end{tabular}

* $N$ represents total number of estimates by $S$ s giving any numerical response. Ten Ss refused to give numerical estimates for any of the stimuli on one problem, one $S$ refused on both, and two Ss gave values for only part of the stimuli. Ss who said, "I don't know" or gave an indeterminate answer (e.g., "lots") were so classified.

changes made them in the direction of correcting an error than in the direction of changing a correct response to an erroneous one. Of 223 changes, $62 \%$ were in the direction of correcting an error. In order of ascending grade level, percentages of change in the direction of correcting responses were $57,56,62$, and 76 . Moreover, nearly all of these responses in the second-grade group occur on Problem I. It appears that, until they have received feedback from their choices on the initial tests, children at all age levels tested generally failed to apply what they had learned during training trials to the tests on new stimulus pairs. Some Ss merely failed to recognize the pairs as different from the training series. Further, only the second-graders on Problem I profited by feedback on the first tests to the extent of shifting significantly from

Table 3

Percentage of Ss Giving Correct Responses on Individual Transfer Trials

\begin{tabular}{|c|c|c|c|c|c|c|c|c|}
\hline & \multicolumn{4}{|c|}{ First Presentation of Pair } & \multicolumn{4}{|c|}{ Second Presentation of Pair } \\
\hline \multirow[b]{3}{*}{ Group } & 4 & 4 & 2 & 2 & 4 & 4 & 2 & 2 \\
\hline & vs & vs & vs & vs & vs & vs & $\mathbf{v s}$ & vs \\
\hline & 1 & 0 & $\mathbf{1}$ & 0 & 1 & 0 & 1 & 0 \\
\hline & \multicolumn{8}{|c|}{ Problem 1} \\
\hline$K-4$ & 68 & 76 & 32 & 72 & 64 & 80 & 40 & 60 \\
\hline $\mathrm{K}-5$ & 64 & 77 & 32 & 68 & 81 & 81 & 41 & 59 \\
\hline First Grade & 73 & 82 & 41 & 68 & 81 & 86 & 41 & 68 \\
\hline Second Grade & 50 & 83 & 25 & 50 & 87 & 83 & 63 & 83 \\
\hline \multirow[t]{2}{*}{ Total } & 63 & 80 & 32 & 65 & 78 & 83 & 46 & 68 \\
\hline & \multicolumn{8}{|c|}{ Problem 2} \\
\hline $\mathrm{K}-4$ & 48 & 76 & 44 & 60 & 52 & 84 & 56 & 80 \\
\hline $\mathrm{K}-5$ & 77 & 91 & 41 & 82 & 73 & 81 & 59 & 77 \\
\hline First Grade & 68 & 91 & 45 & 77 & 86 & 95 & 45 & 82 \\
\hline Second Grade & 91 & 91 & 67 & 87 & 96 & 96 & 75 & 83 \\
\hline Total & 71 & 87 & 49 & 76 & 76 & 89 & 59 & 81 \\
\hline
\end{tabular}

incorrect choices on the first test on a stimulus pair to correct choices on the second.

The frequency with which Ss made correct choices on the transfer trials can be interpreted in two ways. Following the customary usage in the operant conditioning literature, let us denote as $\mathrm{S}+$ the stimulus $\mathrm{S}$ had learned to choose during training on a pair and as $\mathrm{S}-$ the stimulus he had learned not to choose. When, on a 4-1 or 4-0 test, $\mathbf{S}$ chose the higher-valued stimulus, he was merely continuing to choose the $\mathrm{S}+$ he had learned to criterion, though it was now paired with a new S-. As can be seen from Table 3, this tendency was strong and highly significant, although performance showed some deterioration for most groups, especially on the 4-1 problem, when compared to the criterion run (which for both the 4-2 and 1-0 pairs must have been $87 \%$ or higher). However, when $S$ chose the more highly rewarded stimulus on a $2-0$ or 2-1 test, he was choosing a former $\mathrm{S}-$ over another $\mathrm{S}-$ in the first case and an Sin the face of a former $S+$ in the second.

On Problem I, all four groups' correct choices fell to a level not significantly different from chance when the correct choice was a former $S-$, and, indeed, below chance when it was a former $S-$ paired with a former S+. On Problem II, for all age groups the frequencies of choice of the 2 -token block over the 0 -token block were substantially and significantly above chance, although smaller than those on the problems involving the 
4-token stimulus. But for the critical 2-1 combination, choices of the 2-token stimulus rose appreciably above chance only for the second-grade group.

The clearest picture of the age trend in transfer behavior, uncomplicated by learning on the transfer pairs themselves, is given by the proportions correct on the first test of each problem compared to choices just prior to transfer trials; for both Problems I and II, we see no systematic shift on the part of the youngest Ss away from the tendency to "stay with the winner," a tendency which initially characterized all age groups. In contrast, the intermediate age groups make some progress toward a more effective transfer strategy and second-graders show clear transfer on Problem II. It is natural to surmise that this age trend is related to the Ss' ability to verbalize relations between stimuli and reward values. For more direct evidence on this interpretation, we turn to the data on verbalized reward estimation.

Reward Estimation

The number of children giving correct magnitudes when asked what reward values were associated with each stimulus increased with CA, but not in a completely regular fashion. The percentages of $S$ s in successive age groups who gave correct values for all four stimuli when each was presented alone following transfer trials were 0 , 14,9 , and 21 for Problem $I$ and 8,27 , 18, and 50 for Problem II.

Table 4 presents proportions of verbalized expectations by grades for stimuli ordered on the basis of the true value of the rewards associated with them. Although most Ss confined themselves to values of rewards actually used, a few Ss attributed 3 tokens to some stimuli and a few gave values greater than 4 . The increase in accuracy of expectations with age is clearest in the case of values attributed to the stimulus associated with 4 tokens and is least apparent for the 0 -token stimulus. For the combined groups, the true value is the one most frequently given for all four stimuli. With respect to the generalization gradients around the true values, however, especially at the lower ages, there is a major deviation from the monotonic gradients reported for adults (Estes, 1966): namely, a strong tendency to give too many " 4 " responses to the stimuli actually associated with lower reward values. This tendency is most conspicuous in the case of the 1 -token stimulus, which was the other "winner" during training; it can be seen in Table 4 for the total group and for three of the four age groups.

Mean verbalized expectations,

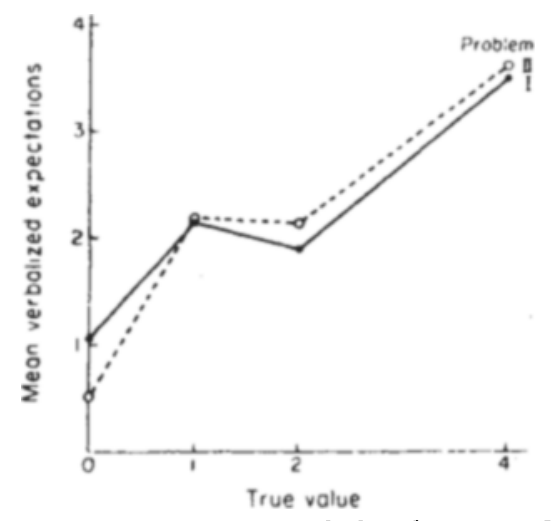

Fig. 1. Mean verbalized reward expectations plotted against true reward magnitudes for Problems I and II.

pooled over grades, are plotted against true values for each problem in Fig. 1. Expectations line up with true values, except for the deviation around 1-and 2 -token stimuli. This inversion is of special interest in that it corresponds to the tendency, observed above, for all Ss to choose the 1-token block over the 2-token block on the first transfer trial of Problem I and for all but the oldest children to choose the 1-token block over the 2-token block on the second transfer trial on Problem I. It also reflects the tendency of some Ss to generalize from one "winner" to the other and to attribute 4 tokens to both training $\mathrm{S}+\mathrm{s}$.

The ordering of estimates for the 2 . and 1-token stimuli may be taken as an index of the extent to which Ss organized the information necessary for transfer on the basis of absolute values. Mean transfer score (number correct out of eight trials for a problem) for subgroups of Ss who gave smaller verbal expectation values for the 2-than for the 1-token block were $4.5(\mathrm{SD}=1.6)$ for Problem I and 5.1 ( $\mathrm{SD}=1.5$ ) for Problem II; comparable scores for the subgroup of Ss giving larger expected values for the 2 -token than for the 1-token stimulus were 6.0 $(\mathrm{SD}=1.5)$ and $6.6 \quad(\mathrm{SD}=1.4)$, respectively. All of these differences were significant at the.001 level $(t=4.07, \quad d f=69, \quad$ and $t=3.95$, $\mathrm{df}=64$, respectively). If we consider transfer scores only for the 2 vs 1 trials themselves, mean scores (out of two possible) were 1.1 and 1.4 for Problem I and Problem II for the group estimating the 2-token stimulus as higher than the 1-token stimulus and .7 and .8 for the group estimating the 2-token stimulus as lower in value than the 1-token stimulus. Only the difference on Problem II was statistically significant $(t=3.2$; $\mathrm{df}=64 ; \mathrm{p}<.01)$. There were no significant or systematic age trends in either of these sets of transfer scores. It seems likely that part of the improvement from Problem I to Problem II can be attributed to the expression of verbalized expectations at the end of Problem I. It is possible that asking the question draws the S's attention to the invariance of reward magnitude associated with the block. However, Ss who can give correct values for all stimuli do not necessarily make perfect scores on the transfer trials. The number of Ss giving correct estimates for all four stimuli increased with age and within ages from Problem I to Problem II; 10 Ss did so on Problem I and had a mean transfer score of $6.6(\mathrm{SD}=1.0)$ as opposed to $5.1(\mathrm{SD}=2.5)$ for the total group; similarly on Problem II, the 24 Ss giving four correct estimates averaged $6.8(\mathrm{SD}=1.2)$ correct responses on transfer trials as opposed to 5.9 $(S D=1.6)$ for the total group. These findings seem to parallel findings from discrimination reversal studies which have led experimenters to distinguish between production deficiencies and mediation deficiencies (Reese, 1962). DISCUSSION

Developmental trends observed in this study include the expected ones-increase in speed of learning with age, increase in correct responses on transfer trials, and increasing ability to verbalize correctly the reward magnitudes associated with the stimuli. Older Ss tend to learn from the transfer trials themselves to a greater extent than younger children.

The 2-1 transfer test, in which the higher-valued stimulus is a former $\mathrm{S}$ and the lower valued stimulus a former $S+$, bears most directly on the question of just what is being learned. Transfer data indicate that none of the groups on Problem I and only second-graders on Problem II chose 2 over 1 more than half of the time; and on Problem I the preference was over $65 \%$ for 1 over 2 in all groups combined. Apparently, young children initially tend to base their responses on approach-avoidance relations, and only with increasing age and experience do they shift to utilizing information about absolute values.

Data on verbal reward expectations show clearly that all of the children, but especially the younger ones, make much less progress toward learning the values of the 2 and 1 blocks than the 4 and 0 blocks. However, as noted above, in cases when children gave higher verbal expectations for the 2 than for the 1 block, their transfer scores on the 2-1 pair were more than $50 \%$ higher than those of Ss who gave lower expected values for 2 than for 1 . Thus, children of all ages studied do tend to base their choices on reward expectations when they have acquired 
the necessary information.

There is, then, no one answer to the question concerning the basis for transfer. Children can transfer on the basis of information concerning absolute reward values when they have successfully discriminated the values and have stored in memory the relations between stimuli and values. At none of the ages studied here do we find any indication that children have acquired the strategy of attending to stimulus-reward relations and utilizing them on transfer choices as a result of prior experience. And only the oldest children make substantial progress in acquiring this strategy as a result of experience in the experimental situation. Thus there appears to be a distinct developmental trend in readiness to acquire the more effective transfer strategy.

\section{REFERENCES}

ATKINSON, R. C., \& WTCKENS, T. D. Human memory and the concept of reinforcement. In $R$. Glaser (Ed.), The nature of reinforcement. New York: Academic Press, 1971. Pp. 66-120.

ESTES. W. K. Transfer of verbal ciscriminations based on differential i e ward magnitudes. Journal of Experimental Psychology, 1966, 72 $376-283$

ESTES, W. K. Reinforcement in human learning. In J. T. Tapp (Ed.). Reinforcement and behavior. New York Academic Press, 1969. Pp. 63-94.

KENDLER, H. H., \& KENDLER, T. S Mediation and conceptual behavior. In $\mathrm{K}$ W. Spence and J. T. Spence (Eds.), The povchology of learning and motivation. Vol. 2. New Yon: Academic Press, 1968. Pp. 197-244

KENDLER, T. S., KENDLER, H. H., \& WELLS, D. Reversal and nonreversal shifts in nursery school children. Journal of Comaprative \& Physiological Psy chology, 1960, 53, 83-88.

MEYER, D. R., LOPOPOLO, M. H., \& SINGH, D. Learning and transfer in the monkey as a function of differential level of incentive. Joumal of Experimental Psychology, 1966, 72, 284-286.

NUTTIN, J., \& GREENWALD, A. G Reward and punishment in human learning. New York: Academic Press, 1968.

REESE, H. N. Verbal mediation as a function of age level. Psychological Bulletin, 1962, 59, 502-509.

THORNDIKE, E. L. Human learning. New York: Century, 1931.

ZEAMAN, D.. \& HOUSE, B. J. The role of attention in retardate discrimination learning. In N. Ellis (Ed.), Handbook of mental deficiency. New York: McGraw-Hill, 1963. Pp. 159-223.

\section{NOTE}

1. The record of one $S$ was not included in the analysis. This $S$ was run before $\mathbf{E}$ became familier with the school's routine and, because it was necessary for this $S$ to leave on the school bus, it was not possible to complete the session. 